\title{
OREVER|
}

\section{Produtos da sociobiodiversidade no PAA e PNAE: instrumentos de gestão operacional no PNAE}

\section{Sociobiodiversity products in the PAA and PNAE: operational management instruments in the PNAE}

\section{Manoel Ricardo Vilhena}

vilhena.ufv@gmail.com

Doutorando em Extensão Rural, Universidade Federal de Viçosa (UFV). Mestre em Política Científica e Tecnológica (DPCT/IG/UNICAMP). Professor do Departamento de Ciências Sociais da UNIFAP.

\section{Almiro Alves Junior}

almiroalves@gmail.com

Doutorando em Extensão Rural, Universidade Federal de Viçosa (UFV). Mestre em Extensão Rural, Universidade Federal de Viçosa (UFV). MBA em Gestão de Negócios (FGV-RIO). Licenciado em História, Universidade Federal de Viçosa (UFV).

\section{Alair Ferreira de Freitas}

alair.freitas@ufv.br

Doutor em Administração, Universidade Federal de Minas Gerais (UFMG). Professor do Departamento de Economia Rural, Universidade Federal de Viçosa (UFV). 


\title{
OREVER|
}

\section{RESUMO}

O artigo analisa a execução de duas políticas públicas de acesso ao mercado institucional - o Programa de Aquisição de Alimentos (PAA) e o Programa Nacional de Alimentação Escolar (PNAE) - e tem por objetivos problematizar a participação dos produtos da sociobiodiversidade nesse mercado e propor alguns instrumentos de identificação da participação e monitoramento desses produtos no PNAE. A metodologia utilizada é baseada em revisão teórica bibliográfica, análise de documentos institucionais, normativas de legislação em vigência e indicadores de resultados. Como resultado, propõe-se que as aplicações desses instrumentos possam tornar mais eficiente a gestão administrativa e operacional do PNAE, ampliando a participação dos produtos da sociobiodiversidade nesse programa.

Palavras-chave: Agroextrativismo; Compras Institucionais; Merenda Escolar.

\begin{abstract}
The article analyzes the implementation of two public policies for access to the institutional market - the Food Acquisition Program (PAA) and the National School Feeding Program (PNAE) - and aims to problematize the participation of sociobiodiversity products in these markets, and to propose some instruments to identify the participation and monitoring of these products in the PNAE. The methodology used is based on the theoretical bibliographical review, analysis of institutional documents, normative legislation in force and indicators of results. As a result, it is proposed that the applications of these instruments could make the administrative and operational management of the PNAE more efficient, increasing the participation of biodiversity products in this program.
\end{abstract}

Keywords: Agroextractivism; Institutional Purchases; School Lunch. 


\section{OREVER}

\section{Introdução}

Nos diversos municípios brasileiros, onde existem plantios e produção intensiva e extensiva, a agricultura familiar (AF) coexiste e, ao mesmo tempo, é profundamente impactada pelas monoculturas de exportação (commodities agrícolas). Entre os impactos mais danosos, está a desestruturação social, econômica e cultural, desencadeada pela perda das práticas relacionadas aos saberes agrícolas, ao manejo dos ecossistemas e à capacidade de criação de pequenos animais. Tais perdas são entendidas como a deslegitimação de valores sociais, dos recursos simbólicos e das práticas societárias baseadas em comunidades.

As pressões territoriais das frentes de expansão da agricultura monocultora levam à perda significativa da biodiversidade e aumentam o risco de degradação ambiental, associada à progressiva homogeneização de territórios, ecossistemas e biomas em diversos lugares do Brasil e do mundo. Para Domingues e Bermann (2012) ao abordar o avanço da cultura da soja,

...do cerrado, expandindo-se, gradativamente, ao norte do Brasil, principalmente por meio de latifúndios monocultores e controlados por grandes empresas transnacionais. A área de avanço agrícola ao norte tem substituído o bioma local: a Floresta Amazônica, o que tem preocupado entidades públicas e privadas, em face do desmatamento exagerado e perda da biodiversidade. (DOMINGUES e BERMANN, 2012, p. 21)

Por décadas o governo brasileiro não concebeu ou executou políticas públicas específicas e universalizadas direcionadas às demandas da agricultura familiar, pelo menos até os anos 1990. Para Grisa e Schneider (2014) “através de muita mobilização e articulação dos movimentos sociais, sindicatos e sociedade civil organizada, começou-se a elaborar planos e projetos voltados para a agricultura familiar, o que resultou na entrada dessa pauta na agenda política do Estado brasileiro".

As políticas públicas voltadas a agricultura familiar, a partir dos anos 1990 marcam um processo gradual de protagonismo e maior visibilidade social dos agricultores familiares com forte impacto na realidade rural, segundo Grisa e Schneider (2014), é possível observar, nesse período, três fases distintas desse processo denominadas de "gerações", que de maneira sintética, são as seguintes:

1) crédito de fomento objetivando aumentar a produção agrícola com a criação do Programa Nacional de Fortalecimento da Agricultura Familiar (Pronaf) em 1995 e a retomada da Política de Assentamentos de Reforma Agrária; 2) Programas com caráter social e assistencialista (Programas Fome Zero, de combate à fome para a população em extrema pobreza, Comunidade Solidária e Bolsa Família; 3) Mercado 


\section{OREVER}

de Compras Institucionais: Programa de Aquisição de Alimentos (PAA) e o Programa Nacional de Alimentação Escolar (PNAE), sendo que $30 \%$ dos seus recursos devem ser utilizados na aquisição de produtos da agricultura familiar, políticas públicas que contribuem para o desenvolvimento rural. (GRISA e SCHNEIDER, 2014, p. 128, p. 134, p. 137)

É válido destacar que no desenho institucional das políticas para a agricultura familiar houve delimitação objetiva quanto a definição de população muito pobre, de extrema pobreza e de vulnerabilidade à fome localizada no meio rural diferenciando-se daquela localizada nas grandes cidades. Essa distinção espacial será fundamental para estabelecer um quadro abrangente e qualificado de propostas mais articuladas e integradas para fortalecer a execução do Programa Fome Zero.

A questão do combate à pobreza extrema por meio de políticas públicas de iniciativa do Estado brasileiro ocorre em uma conjuntura de grave crise social e econômica e econômica com desemprego estrutural, insuficiência alimentar, baixa renda para consumo, entre outros. A implementação de políticas articuladas e com objetivos bem definidos será fundamental. Nesse sentido, autores como Silva et al. (2010) no estudo Fome Zero: a experiência brasileira,

a articulação entre políticas estruturais, políticas específicas e políticas locais, direcionadas ao atendimento de grupos diferenciados, vinculado a ações emergenciais de curto, médio e longo prazo, resulta na ampliação do acesso a alimentos por parte das populações em situação de extrema pobreza. (SILVA et al., 2010, p. 22, 24, 30)

Importante destacar que nos objetivos gerais no âmbito do Programa Fome Zero, buscou-se articular as dimensões de alcance social, vinculado ao econômico articulado com diversas ações e atividades emergenciais e outras permanentes, capazes de gerar acesso à alimentação para a população de baixa renda (vulnerabilidade à fome), na melhoria da renda e no aumento da oferta de alimentos básicos, todas centrada na política de Segurança Alimentar e Nutricional (SAN). O quadro esquemático a seguir representa as diversas ações como componentes das políticas do Programa. 


\section{OREVERT:

\section{Esquema das propostas do Projeto Fome Zero}

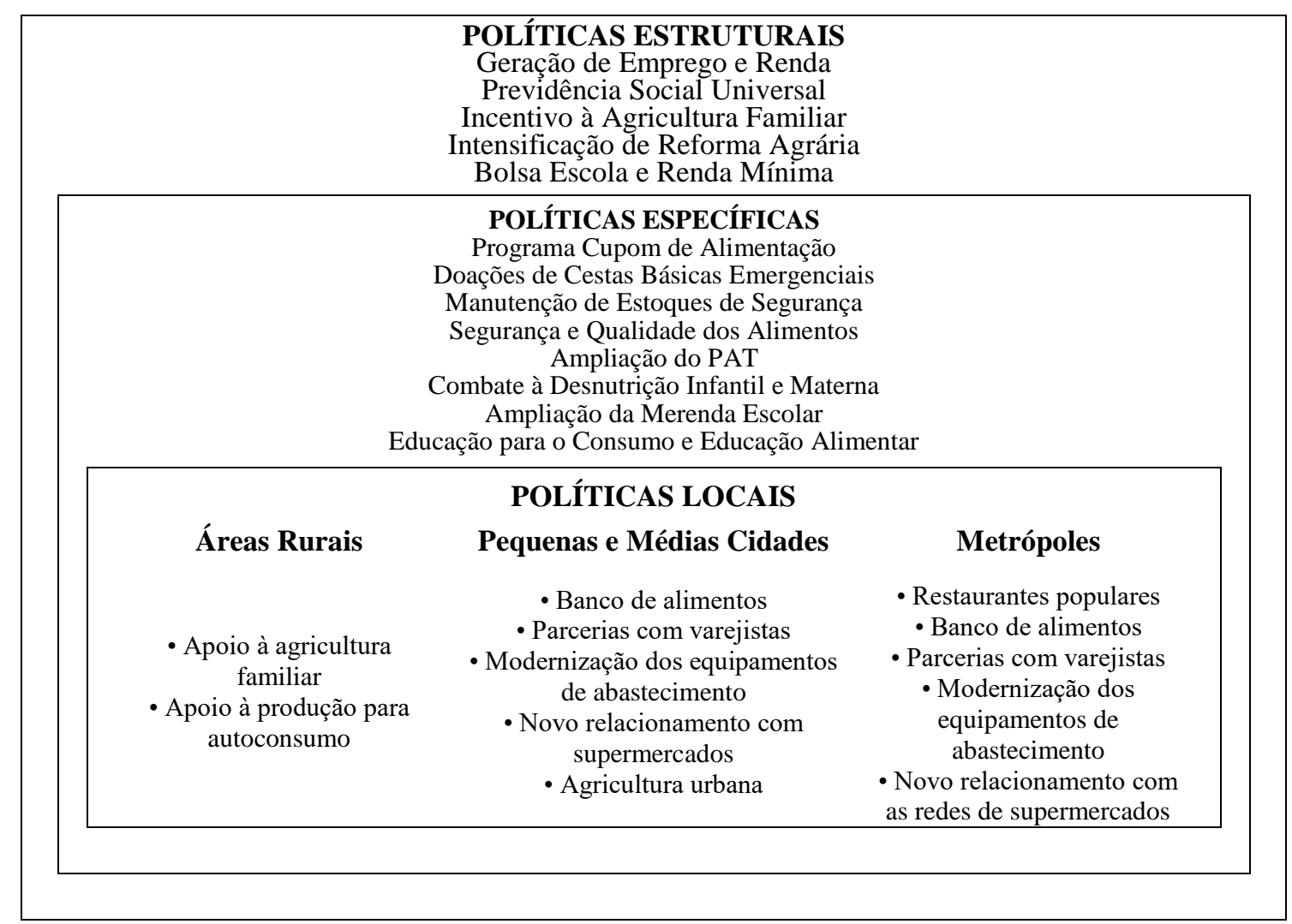

Fonte: Silva (2010, p.20).

No conjunto das ações direcionadas a agricultores em situação de vulnerabilidade social e baixo capital, políticas públicas mais específicas e direcionadas foram criadas e implementadas como destacado por Grisa e Schneider (2014, p. 135):

o Pronaf continuou com seu papel de destaque, e também foram criados serviços adicionais como o Pronaf B (1997); o Programa Garantia Safra (2002); o Programa Desenvolvimento Sustentável de Territórios Rurais (Pronat, em 2003); o Programa de Habitação Rural (PNHR, 2003); o Programa Territórios da Cidadania (PTC, 2008), o Programa de Fomento às Atividades Produtivas Rurais no Plano Brasil Sem Miséria (2011), entre outros (GRISA e SCHNEIDER, 2014, p. 135).

De acordo com os mesmos autores, esse movimento proporcionou aos pequenos municípios brasileiros a oportunidade de fomentar a inclusão do pequeno agricultor no processo licitatório de aquisição de produtos, antes vedado a ele por conta do complexo processo burocrático dado pela Lei de Licitações, a Lei no 8.666, 21/06/1993 (BRASIL, 1993).

Nesse contexto, é importante se estabelecer as diferenças entre agricultura familiar e não familiar. A primeira traz características importantes como a integração da família e do trabalho, independentemente da renda ou uso de tecnologias. De acordo com Freitas e 


\section{OREVER}

Freitas (2013), o termo Agricultura Familiar "se refere a uma diversidade de atores que têm em comum a ligação com o campo por meio de alguma atividade agrícola, caracterizada pela utilização dos recursos naturais de que dispõe e pelo emprego de mão de obra familiar".

Para demonstrar essas diferenças e particularidades presentes na agricultura brasileira, o Instituto Brasileiro de Geografia e Estatísticas (IBGE) realizou uma tabulação especial com os dados do Censo Agropecuário 2006, caracterizando melhor os resultados mais significativos da agricultura familiar e da agricultura não familiar.

A título de comparação, observando-se os resultados gerais, é perceptível a importância da dimensão da agricultura familiar (definida na Lei no 11.326/06), na qual a área de propriedade rural não pode ser superior a 04 módulos fiscais ${ }^{1}$. Classificadas como pequenas propriedades, correspondem a 48,0\% dos estabelecimentos rurais, ocupando apenas 2,3\% das terras agrícolas. De outra maneira, 0,9\% das propriedades ocupavam $45 \%$ das terras com cultivo da agropecuária.

No Censo Agropecuário (IBGE, 2006), foram identificados 4.367 .902 estabelecimentos da agricultura familiar, ou 84,4\% do total apurado, ocupando 80,25 milhões de hectares, ou seja, 24,3\% da área dos estabelecimentos agropecuários brasileiros. No mesmo levantamento, os estabelecimentos não familiares representavam 15,6\% do total, porém, ocupando 75,7\% da área.

Os dados apresentados revelam a importância da agricultura familiar na formação da cesta básica de alimentos essenciais à segurança alimentar nutricional, pois os produtos mais expressivos foram: $87 \%$ da produção nacional de mandioca, $70 \%$ da produção de feijão, $46 \%$ do milho, $38 \%$ do café (parcela constituída por $55 \%$ do tipo robusta ou conilon e $34 \%$ do arábica), 34\% do arroz, $58 \%$ do leite (composta por $58 \%$ do leite de vaca e $67 \%$ do leite de cabra), 59\% do plantel de suínos, 50\% das aves, 30\% dos bovinos e, ainda, $21 \%$ do trigo (IBGE, 2006).

A cultura com menor participação da agricultura familiar foi à soja (16\%). Isso demonstra um contraponto com a agricultura comercial, concentrada em poucos produtos, cultivos em larga escala de produção e destinados ao mercado externo. De maneira geral,

\footnotetext{
${ }^{1}$ EMBRAPA (2019): Módulo fiscal é uma unidade de medida, em hectares, cujo valor é fixado pelo Incra para cada município levando-se em conta: (a) o tipo de exploração predominante no município (hortifrutigranjeiro, cultura permanente, cultura temporária, pecuária ou florestal); (b) a renda obtida no tipo de exploração predominante; (c) outras explorações existentes no município que, embora não predominantes, sejam expressivas em função da renda ou da área utilizada; e (d) o conceito de "propriedade familiar". A dimensão de um módulo fiscal varia de acordo com o município onde está localizada a propriedade. $\mathrm{O}$ valor do módulo fiscal no Brasil varia de 5 a 110 hectares.
} 


\section{OREVER}

a agricultura familiar produz de $70 \%$ dos alimentos consumidos, ocupa $74 \%$ da mão de obra e alcança $10 \%$ do Produto Interno Bruto.

Os agricultores familiares e seus beneficiários foram definidos na Lei nº 11.326/06 e a produção agrícola passaram a contar com alternativas de mercado através das seguintes políticas públicas de Compras Institucionais: Programa de Aquisição de Alimentos (PAA - Lei $n^{\circ} 10.696$, de 2/07/2003; Art. 19 regulamentado pelo Decreto ${ }^{\circ}$ 7.775, de 4/07/2012); Programa Nacional de Alimentação Escolar (PNAE - Lei ${ }^{\circ}$ 11.947/2009); e Política de Garantia de Preços Mínimos (PGPM, regulamentado pelo Decreto-lei n. ${ }^{\circ}$ 79, de 1966).

O PAA e o PNAE apresentam traços comuns quanto a seus objetivos e finalidades básicas, como: ampliar a oferta e demanda por gêneros alimentícios diversificados, produzidos em âmbito local, preferencialmente da agricultura familiar; possibilitar maior acesso a alimentos que respeitem as diferenças biológicas e condições de saúde de consumidores e estudantes; e proporcionar oportunidades de acesso e diversificação para a população em vulnerabilidade social.

Com o esforço de demonstrar as principais políticas direcionadas à agricultura familiar e extrativismo, de acordo com seu marco regulatório, Leis, Portarias e Decretos, associados a suas principais diretrizes, foram descritos e sistematizados no quadro a seguir. 


\section{A Regulação da Agricultura Familiar e Extrativismo no Brasil}

\begin{tabular}{|c|c|c|}
\hline $\begin{array}{l}\text { Políticas de Mercado } \\
\text { Institucional }\end{array}$ & Marco Legal x Regulação & Diretrizes e Importância \\
\hline Agricultura Familiar & $\begin{array}{l}\text { - Lei no } 11.326 / 2006,24 / 07 / 2006 \\
\text { - Portaria MDA no } 111 \text {, de } \\
\text { 20/11/2003 e Resolução no } 3.467 \\
\text { de } 02 / 07 / 2007 .\end{array}$ & $\begin{array}{c}\text { - Definiçãa de Agricultura Familiar e } \\
\text { beneficiários diretos: agricultores familiares; } \\
\text { assentados; povos e comunidades } \\
\text { tradicionais; indígenas; extrativistas; } \\
\text { pescadores artesanais. } \\
\text { - Público preferencial do Mercado } \\
\text { Institucional }\end{array}$ \\
\hline Pronaf & & $\begin{array}{l}\text { - Promover o desenvolvimento sustentável do } \\
\text { segmento rural, de agricultores familiares, de } \\
\text { modo a propiciar-lhes o aumento da }\end{array}$ \\
\hline $\begin{array}{l}\text { Programa Nacional } \\
\text { de Fortalecimento da } \\
\text { Agricultura Familiar }\end{array}$ & $\begin{array}{l}\text { - Decreto } n^{\circ} 1.946, \text { de } 28 \text { de } \\
\text { junho de } 1996 .\end{array}$ & $\begin{array}{l}\text { capacidade produtiva, a geração de empregos } \\
\text { e a melhoria de renda. } \\
\text { - Pronaf: o cap. } 10 \text { do Manual de Crédito }\end{array}$ \\
\hline & & $\begin{array}{l}\text { Rural (MCR) enquadra os produtores rurais } \\
\text { familiares nos grupos a seguir especificados, } \\
\text { comprovados mediante Declaração de }\end{array}$ \\
\hline DAP & & \\
\hline $\begin{array}{c}\text { Declaração de } \\
\text { Aptidão ao Pronaf }\end{array}$ & & $\begin{array}{l}\text { C/D/E); Grupo A/C. } \\
\text { - DAP: é o instrumento de identificação do } \\
\text { agricultor familiar para acessar políticas } \\
\text { públicas, como o Pronaf. }\end{array}$ \\
\hline & $\begin{array}{l}\text { - Lei de Criação: Lei n. }{ }^{\circ} 10.696 \text {, } \\
\text { de } 2 \text { de julho de } 2003 \text { (Art. 19): }\end{array}$ & - Compra Direta da Agricultura Familiar - \\
\hline PAA & $\begin{array}{c}\text { - Regulamento: Decretos } 6.447 \\
\text { de } 07 / 05 / 2008 \text { e } 6.959 \text { de } \\
16 / 09 / 2009\end{array}$ & $\begin{array}{c}\text { - Atender a um público em situação (ou risco) } \\
\text { de insegurança alimentar (PAA Doação } \\
\text { Simultânea): creches públicas, entidades }\end{array}$ \\
\hline $\begin{array}{l}\text { Programa de } \\
\text { Aquisicão de }\end{array}$ & $\begin{array}{l}\text { - Resoluções do Grupo Gestor } \\
\text { (44 resolucões): }\end{array}$ & $\begin{array}{c}\text { assistenciais, escolas da rede pública estadual } \\
\text { e municipal. }\end{array}$ \\
\hline Alimentos & & $\begin{array}{l}\text { - Atuar na formação de estoques estratégicos } \\
\text { (PAA Formacão de Estoques). }\end{array}$ \\
\hline & - Política Nacional de SAN: & - Valor máximo de R\$ 8.000,00 por DAP \\
\hline & $\begin{array}{c}\text { Decreto } \text { n. }^{\circ} 7.272 \text {, de } 25 \text { de } \\
\text { agosto de } 2010\end{array}$ & $\begin{array}{l}\text { Física ou Jurídica do produtor individual ou } \\
\text { através de Associação ou Cooperativa. }\end{array}$ \\
\hline PNAE & - Lei n. ${ }^{\circ} 11.947 / 2009$ & $\begin{array}{l}\text { - Realizar compras de produtos } \\
\text { regionalizados para merenda escolar da } \\
\text { agricultura familiar e extrativista. } \\
\text { - Aplicação do valor total (R\$) às operações } \\
\text { de compras do PNAE: }\end{array}$ \\
\hline $\begin{array}{l}\text { Programa Nacional } \\
\text { de Alimentação }\end{array}$ & blução & $\begin{array}{l}\text { a) } 70 \% \text { de produtos industrializados (Edital de } \\
\text { Pregão Presencial); }\end{array}$ \\
\hline Fccolor & $\begin{array}{l}\mathrm{n}^{\circ} 38 \text {, Conselho Deliberativo do } \\
\text { FNDE. }\end{array}$ & $\begin{array}{l}\text { b) } 30 \% \text { de produtos da agricultura familiar } \\
\text { (mínimo obrigatório, por Chamada Pública). } \\
\text { - Valor máximo de R } \$ 20.000,00 \text { por DAP } \\
\text { Física ou Jurídica do produtor individual ou } \\
\text { através de Associação ou Cooperativa. }\end{array}$ \\
\hline \multirow{3}{*}{$\begin{array}{l}\text { Política de Garantia } \\
\text { de Preços Mínimos } \\
\text { para Produtos da } \\
\text { Sociobiodiversidade }\end{array}$} & $\begin{array}{l}\text { - Decreto-Lei no } 79 / 66 \text { : } \\
\text { instituição de preços mínimos e } \\
\text { aquisição de produtos } \\
\text { agropecuários. }\end{array}$ & \multirow{2}{*}{$\begin{array}{c}\text { - Estabilidade dos preços dos produtos; } \\
\text { - Estabilidade da renda dos extrativistas; } \\
\text { - Regularidade do fluxo de produção e } \\
\text { comercialização; } \\
\text { - Regularização dos produtores e dos } \\
\text { atravessadores (DAP e Nota Fiscal); } \\
\text { - Manter a ocupação de mão de obra no meio } \\
\text { rural; } \\
\text { - Organização da produção em cooperativas; } \\
\text { - Estímulo à utilização de BPP e aumento da } \\
\text { produção. }\end{array}$} \\
\hline & $\begin{array}{c}\text { - Lei no 11.775/2008: instituição } \\
\text { da modalidade de Subvenção } \\
\text { Direta. }\end{array}$ & \\
\hline & $\begin{array}{l}\text { - Portaria Interministerial } \mathrm{n}^{\mathbf{0}} \\
\text { 239/2009; } \\
\text { - Plano Nacional de Promoção } \\
\text { das Cadeias de Produtos da } \\
\text { Sociobiodiversidade (PNPSB) }\end{array}$ & $\begin{array}{l}\text { - Desenvolver ações integradas para a } \\
\text { promoção e o fortalecimento das cadeias de } \\
\text { produtos da sociobiodiversidade, com } \\
\text { agregação de valor e consolidação de } \\
\text { mercados sustentáveis. }\end{array}$ \\
\hline
\end{tabular}

Fonte: MDA/MDSA, 2017. Elaboração e sistematização dos autores, novembro de 2017. 


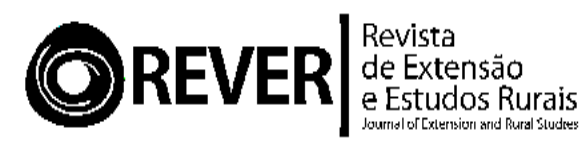

É inegável que o PAA e o PNAE de maneira progressiva se tornaram importantes políticas públicas para a agricultura familiar oportunizando vendas para um mercado institucional, com regras menos burocratizadas e público bem definido. Contudo, não é condição suficiente para que milhares de agricultores consigam efetuar suas vendas, pois existe uma enorme diferenciação de produtos característicos do público que constitui a diversidade da agricultura familiar: silvicultores; aquicultores; extrativistas; pescadores. Essa diferenciação de produtos por si só, não garante a inserção efetiva dos produtos nos programas, pois existem exigências adicionais como atender a padrões higiênico e sanitário, regularidade na entrega de produtos, cumprimento de contratos, entre outras condicionantes.

E, para os órgãos institucionais que operacionalizam esses programas, como Fundo Nacional de Desenvolvimento da Educação (FNDE/MEC), Secretarias Estaduais e Municipais de Educação, Institutos Federais de Educação, Prefeituras Municipais, etc., é importante monitorar, orientar, fiscalizar e atestar a eficiência e eficácia quanto ao crescimento do número de agricultores e beneficiários, renda gerada, quantidade, valor pago e expansão na diversidade de produtos adquiridos quanto à origem.

Como garantir, então, instrumentos simplificados que possam servir à gestão administrativa e que sejam adequados para identificar no âmbito dos produtos comercializados a presença de produtos do agroextrativismo familiar? Existem diversas dificuldades na execução e gestão operacional desses programas, em razão de os próprios compradores públicos não possuírem instrumentos administrativos eficientes de acompanhamento, intervenção e melhoria, que possam aperfeiçoar a gestão operacional desses programas, em particular do PNAE.

O presente trabalho não pretende destacar ou descrever quais são os instrumentos de controle, monitoramento, acompanhamento e gestão adotados e executados no âmbito do PNAE. A intenção é destacar brevemente os principais produtos comercializados no PAA e PNAE, contribuindo para sugerir alguns instrumentos simplificados que podem ajudar na identificação de importante parcela de produtos comercializados advindos do agroextrativismo (da sociobiodiversidade).

De acordo com o Ministério do Meio Ambiente (MMA, 2018) objetivando estimular o crescimento da participação de produtos agroextrativistas (dos biomas: Amazônia, Cerrado, Pantanal, Caatinga, Mata Atlântica, Zona Costeira Marinha, Pampa) em mercados institucionais, o governo federal, através da Portaria Interministerial MDA/MDS/MMA no 239, de 21/07/09, criou o Plano Nacional para a Promoção dos 


\section{OREVER}

Produtos da Sociobiodiversidade (PNBSB), para promover a conservação e o uso sustentável da biodiversidade e garantir alternativas de geração de renda para as comunidades rurais, por meio do acesso às políticas de crédito, à assistência técnica e extensão rural, aos mercados e instrumentos de comercialização e à política de garantia de preços mínimos ${ }^{2}$.

De acordo com o Ministério do Desenvolvimento Agrário (MDA, 2015) uma definição para Sociobiodiversidade seria dado pela relação entre bens e serviços gerados a partir de recursos naturais, voltados à formação de cadeias produtivas de interesse de povos e comunidades tradicionais e de agricultores familiares. Assim sendo, o governo federal buscou implementar ações voltadas à promoção dos produtos da sociobiodiversidade na economia formal: a) agregação de valor socioambiental; b) geração de renda; c) segurança alimentar de povos, comunidades tradicionais e agricultores familiares.

Portanto, será considerada, neste trabalho, a identificação de produtos agroextrativos da sociobiodiversidade no mercado institucional do PNAE, sugerindo-se uma lista de instrumentos que podem ser aplicados para identificação de sua comercialização, tais como: formulário quantitativo, organizado para obtenção de informações relevantes, capazes de informar qual produto foi comercializado, quanto foi adquirido, preço, quantidade, produtor, entidade que adquiriu, entre outras informações relevantes, de forma a contribuir para as avaliações dos resultados alcançados no PNAE.

A Portaria Interministerial $n^{\circ}$ 01/2016 incorporou o PNPSB ao II Plano Nacional de Agroecologia e Produção Orgânica (PLANAPO), a partir de debates, propostas e resoluções realizadas em maio de 2015, durante o II Seminário Nacional da Sociobiodiversidade. Importante observar que diversos planos foram elaborados e buscaram estabelecer critérios e condições de operacionalizar a comercialização de produtos da agricultura familiar. Seguindo uma linha cronológica, descrevem-se alguns dos mais importantes:

\footnotetext{
${ }^{2}$ O PNPSB foi coordenado pelos Ministérios do Meio Ambiente (MMA), do Desenvolvimento Agrário (MDA), do Desenvolvimento Social e Combate à Fome (MDS) e pela Companhia Nacional de Abastecimento (CONAB). As ações foram focadas em 6 eixos: 1) promoção e apoio à produção e ao extrativismo sustentável; 2) estruturação e fortalecimento dos processos industriais; 3) estruturação e fortalecimento de mercados para os produtos da sociobiodiversidade; 4) fortalecimento da organização social e produtiva; 5) ações complementares para fortalecimento das cadeias de produtos da sociobiodiversidade; 6) ações complementares para a valoração dos serviços da sociobiodiversidade. (MMA, 2018)
} 


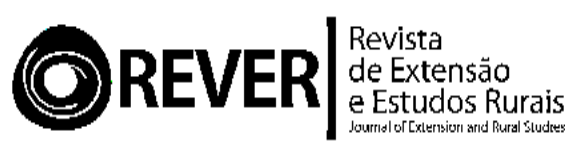

- Plano Nacional de Agroecologia e Produção Orgânica (PLANAPO). Instituído pelo Decreto n ${ }^{\text {o }}$ 7.794, de 20/08/2012.

- Plano Nacional de Desenvolvimento Sustentável dos Povos e Comunidades Tradicionais de Matriz Africana. Instituído pelo Decreto nº 8.750, de 9/05/2016.

- Plano dos Arranjos Produtivos Locais (APL's) de Produtos da Sociobiodiversidade. 2017. Instituído pelo Decreto $n^{\circ}$ 7.775/2017.

- Plano Nacional de Fortalecimento das Comunidades Extrativistas e Ribeirinhas (PLANAFE). Instituído pelo Decreto nº 9.334, de 5/04/2018.

\section{Metodologia}

Esta pesquisa apresenta caráter qualitativo/descritivo e, quanto ao método, consiste em um estudo de caso. De acordo com Yin (2010, p.15), um estudo de caso "estuda um fenômeno em seu contexto real" e tem como objeto de análise uma entidade bem definida. Esse tipo de estudo proporciona conhecimento amplo e detalhado sobre o fenômeno estudado que segundo Gil (2008, p.137), visa conhecer o "como" e o "porquê" que definem seu objeto como único, apresentando suas características identitárias próprias. Faz uso de uma grande variedade de instrumentos e estratégias de coletas de dados, além de possuir um forte cunho descritivo.

Para a coleta de dados referentes à análise das políticas de compras institucionais no âmbito do PAA e PNAE, foi realizada uma pesquisa teórico-bibliográfica de artigos, livros, assim como análise de documentos institucionais, como relatórios técnicos, normativas de legislação em vigência e indicadores de resultados.

Em particular, foram consultados $\mathrm{e}$ analisados os dados qualitativos $\mathrm{e}$ quantitativos disponíveis no Relatório técnico de avaliação do Programa de Aquisição de Alimentos (PAA) e do Programa Nacional de Alimentação Escolar (PNAE), relativo aos produtos da sociobiodiversidade, e no Balanço parcial das atividades do Plano Nacional da Sociobiodiversidade de 2012, publicado em 2011(PNUD, 2011).

Houve também observação participante do primeiro autor deste artigo, na condição de consultor nacional do Plano Nacional de Promoção das Cadeias de Produtos da Sociobiodiversidade (PNPSB - Termo de Referência $n^{\circ} 136547$, Projeto PNUD BRA/11/009), executado no âmbito da Diretoria de Geração de Renda e Agregação de Valor (DGRAV), na Secretaria de Agricultura Familiar (SAF) do Ministério do Desenvolvimento Agrário (MDA), nos anos de 2012 e 2013. Entre os objetivos estavam: 


\section{OREVER|}

a qualificação da gestão, das principais ações e da operacionalização de implantação e o monitoramento do Plano de Ação das Cadeias de Produtos da Sociobiodiversidade.

Destaque-se, ainda, a realização de uma Oficina de Planejamento Estratégico centrado na construção de instrumentos de monitoramento e avalição do PNPSB (realizado em fevereiro de 2011), como importante momento de reflexão sobre a organização de instrumentos de formatação e a definição de indicadores para avaliação do PNPSB, elaborados como possíveis soluções.

\section{Resultados E Discussão}

\section{Produtos da Sociobiodiversidade no PAA}

A concepção de criação do PAA é decorrente das ações do Programa Fome Zero, que objetivou combater à fome e garantir Segurança Alimentar e Nutricional (SAN). O programa foi institucionalizado formalmente pela Lei $\mathrm{n}^{\circ}$ 10.696, de 2/07/2003 (BRASIL, 2003), e compreende ações de apoio à produção, distribuição, doação e estocagem dos produtos agropecuários da Agricultura Familiar. Nesse aspecto é um programa inovador e avança em relação ao modelo agrícola em vigência no Brasil, voltado a privilegiar o agronegócio.

A necessidade de viabilizar a implementação de uma política pública que seja capaz de articular, ou integrar, os principais atores institucionais em uma estratégia de rede de políticas públicas com um Plano de Ação definido, é fundamental para políticas como o PAA e PNAE. Neste sentido, PICCIN (SEAD, 2016), aborda os diversos aspectos referentes à superação de gargalos, como a criação de espaços de coordenação e articulação estaduais de comercialização e abastecimento dos produtos da Sociobiodiversidade e da Agricultura Familiar, caso das Câmaras de Comercialização nos Estados da Amazônia.

Dados da Companhia Nacional de Abastecimento (CONAB, 2017, p.9) indicam que os recursos previstos para execução do PAA são direcionados para atender duas modalidades - a) PAA Formação de Estoque (Ministério do Desenvolvimento Agrário MDA); b) PAA Doação Simultânea (Ministério do Desenvolvimento Social - MDS) -, totalizando, no período de 2003 a 2010, R\$ 3.392.380.000,00. Nesse intervalo, o crescimento foi de $369,74 \%$ no volume de recursos executados. Participaram dessas modalidades de compras governamentais 945.232 agricultores familiares, e a média de expansão, nos últimos quatro anos, foi de 149.950 agricultores participantes. 


\section{OREVER|縉

Em 2009, as operações mobilizaram investimentos de $\mathrm{R} \$$ 7.400.000,00, contemplando 1.860 beneficiários e 4,2 toneladas de produtos da agricultura familiar. No período de 2009 a 2011, a média em kg/produtor cresceu de 44,30 para 52,30, respectivamente. Ao verificar o valor operacionalizado por família, a partir da relação total de investimentos versus número de beneficiários, obtém-se o valor de R \$ 3.978,49 (2009), que cresceu para $\mathrm{R} \$ 4.070,36$ (2012), em média, por família de agricultor familiar beneficiário, conforme Tabela 1 (BRASIL/PNUD, 2012).

Tabela 1: Operações com Produtos da Sociobiodiversidade (2009 a 2012)

\begin{tabular}{cccccc}
\hline Ano & R\$ (Milhões) & $\begin{array}{c}\mathbf{N}^{\mathbf{*}} \text {. } \\
\text { Beneficiários }\end{array}$ & $\begin{array}{c}\text { Quantidade } \\
\text { (ton.) }\end{array}$ & $\begin{array}{c}\text { Média (R\$/ } \\
\text { Beneficiário) }\end{array}$ & $\begin{array}{c}\text { Média (Kg/ } \\
\text { Produto) }\end{array}$ \\
\hline $\mathbf{2 0 0 9}$ & $7.400 .000,00$ & 1.860 & $4.200,00$ & $3.978,49$ & 44,30 \\
\hline $\mathbf{2 0 1 0}$ & $11.500 .000,00$ & 2.919 & $5.500,00$ & $3.939,71$ & 53,10 \\
\hline $\mathbf{2 0 1 1}$ & $15.700 .000,00$ & 3.925 & $7.500,00$ & $4.000,00$ & 52,30 \\
\hline $\mathbf{2 0 1 2}$ & $3.292 .925,00$ & 809 & $2.800,00$ & $4.070,36$ & 28,90 \\
\hline Total & $\mathbf{3 7 . 8 9 2 . 9 2 5 , 0 0}$ & $\mathbf{9 . 5 1 3}$ & $\mathbf{2 0 . 0 0 0 , 0 0}$ & $\mathbf{1 5 . 9 8 8 , 5 6}$ & \\
\hline
\end{tabular}

Fonte: Adaptado de CONAB/DIPAI/SUPAF/SUGOV (2012).

O PAA compreende ações de apoio à produção, distribuição, doação e estocagem dos produtos agropecuários da agricultura familiar, a fim de "garantir o acesso aos alimentos em quantidade, qualidade e regularidade necessárias às populações em situação de insegurança alimentar e nutricional e promover a inclusão social no campo por meio do fortalecimento da agricultura familiar" (BRASIL, 2006). Nesse aspecto é um programa de caráter inovador e que avança em relação ao modelo agrícola de commodities para exportação. Sua valorização é importante por incorporar uma série de aspectos listados a seguir.

De maneira geral, as vantagens de execução do PAA são: (a) escoamento e estabilização da venda da produção da agricultura familiar - organiza de maneira estruturada, o apoio à produção familiar, buscando garantir a renda de maneira regular, ao assegurar uma demanda por meio do mercado institucional; $(b)$ assegurar a produção de alimentos para consumo e para formação dos estoques - tem caráter inovador ao permitir a aquisição de alimentos produzidos pela agricultura familiar com realização de seleção simplificada (Edital de Chamada Pública); (c) considerar a sazonalidade dos produtos - a comercialização pode ser programada para quando houver disponibilidade do produto na safra, e respeitando o calendário agrícola da região e o volume produzido; (d) estimular a participação de organizações coletivas de agricultores familiares - 


\title{
OREVER|
}

cooperativas e associações; (e) promover a Segurança Alimentar e Nutricional (SAN) de populações atendidas por programas sociais na região em que são produzidos.

Apesar desses aspectos, cabe destacar que a aplicação prática do programa ainda encontra resistência em algumas Prefeituras e Secretarias Estaduais de Agricultura e Educação, que tendem a dar preferência a produtos beneficiados, como é possível perceber na pesquisas realizadas por Camargo et al (2013) e Baccarin et al. (2011), ao analisarem o PAA e PNAE e as chamadas públicas de algumas prefeituras suas influencias sobre a realidade dos agricultores familiares brasileiros. Nestes trabalhos verificou-se existir importantes barreiras logísticas para a operacionalização do programa, dentre os quais foram destacados: (i) elevado número de pontos de entrega; (ii) presença de produtos industrializados; (iii) adequação sanitária, principalmente para produtos de origem animal.

O Programa de Aquisição de Alimentos (PAA) é voltado para a aquisição de produtos da produção agrícola familiar destinados a atender pessoas em situação (ou risco) de insegurança alimentar (PAA Doação Simultânea - creches públicas, entidades assistenciais, escolas da rede pública estadual e municipal), e à formação de estoques estratégicos (PAA Formação de Estoques). O valor máximo de aquisição é de R\$ 8.000,00 por DAP Física ou Jurídica do produtor individual ou através de Associação ou Cooperativa.

Dentro do universo contido no mercado institucional do PAA, esta pesquisa destaca a participação de produtos da Sociobiodiversidade, pois segundo Machado, Alves Junior e Freitas (2017, p.14):

\begin{abstract}
sua importância está no processo de garantir a permanência no meio rural, que contribui para a implantação de projetos sustentáveis, assegurando oportunidade de obtenção de novas fontes de renda aos Povos e Comunidades Tradicionais e a Agricultores Familiares, refletindo na qualidade de vida e na conservação da biodiversidade local. Assim, as práticas extrativistas se tornam objeto de interesse dentro do PAA, visto que o "extrativismo está intrinsecamente ligado à história dessas comunidades e continua a ser uma prática econômica e de identidade cultural importante de sua população. (MACHADO, ALVES JUNIOR e FREITAS, 2017, p.14)
\end{abstract}

Sob essa perspectiva, é possível observar, ao longo do tempo, uma evolução gradual na participação dos produtos da sociobiodiversidade no PAA (listados como originários da biodiversidade e operados pela CONAB) e, consequentemente, uma maior contribuição de produtos de origem extrativista entre os anos de 2003 e 2011. Observase, na Tabela 2, que, além do crescimento da variedade de espécies, também existe um 


\section{OREVER

movimento de processamento dos alimentos, gerando novos produtos manufaturados ao longo do tempo.

Isso é relevante na medida em que há essa modernização dos processos e a transformação de produtos in natura, que, além de gerarem maior rentabilidade, acabam por incluir formalmente as mulheres na organização econômica familiar, tirando-as de um papel "invisível”3 nesse processo. Outro fator destacado por Mota et al. (2014, p.10) é a diversificação dos trabalhos instituídos nas comunidades, a partir do funcionamento do PAA localmente, que deu visibilidade e atuação às mulheres em atividades de organização e estruturação da comercialização, tais como coordenação da logística de entregas e contabilidade dos empreendimentos coletivos criados para comercialização.

Tabela 2: Produtos da Sociobiodiversidade na Comercialização do PAA

\begin{tabular}{|c|c|c|c|c|c|c|c|c|c|c|}
\hline $\mathbf{N}^{0}$. & $\begin{array}{c}\text { Produtos } \\
\text { Sociobiodiversidade }\end{array}$ & 2003 & 2004 & 2005 & 2006 & 2007 & 2008 & 2009 & 2010 & 2011 \\
\hline 1 & Açaí & & & & $\mathrm{X}$ & $\mathrm{X}$ & $\mathrm{X}$ & & $\mathrm{X}$ & $\mathrm{X}$ \\
\hline 2 & Amêndoa do Licuri & & & & & & $X$ & & & \\
\hline 3 & Azeite de Babaçu & & & & $\mathrm{X}$ & $\mathrm{X}$ & $X$ & $\mathrm{X}$ & $\mathrm{X}$ & $\mathrm{X}$ \\
\hline 4 & Doce de Buriti & & & & $\mathrm{X}$ & & & & $\mathrm{X}$ & $\mathrm{X}$ \\
\hline 5 & Castanha de Babaçu & & & & $\mathrm{X}$ & & $\mathrm{X}$ & $\mathrm{X}$ & $\mathrm{X}$ & $\mathrm{X}$ \\
\hline 6 & Castanha do Brasil & $\mathrm{X}$ & $X$ & $X$ & $\mathrm{X}$ & $\mathrm{X}$ & $X$ & $X$ & $\mathrm{X}$ & $\mathrm{X}$ \\
\hline 7 & Cupuaçu & & & & $\mathrm{X}$ & $\mathrm{X}$ & $\mathrm{X}$ & $\mathrm{X}$ & $\mathrm{X}$ & $\mathrm{X}$ \\
\hline 8 & Farinha de Baru & & & $X$ & $\mathrm{X}$ & & & & & \\
\hline 9 & Jenipapo & & & & $\mathrm{X}$ & & $X$ & & $\mathrm{X}$ & $X$ \\
\hline 10 & Mesocarpo de Babaçu & & $\mathrm{X}$ & & $\mathrm{X}$ & & $X$ & & & \\
\hline 11 & Pequi & & $\mathrm{X}$ & $\mathrm{X}$ & $\mathrm{X}$ & & & & $\mathrm{X}$ & $\mathrm{X}$ \\
\hline 12 & Urucum & & & & & $\mathrm{X}$ & $X$ & $X$ & $\mathrm{X}$ & $\mathrm{X}$ \\
\hline 13 & Doce de Umbu & & & & & & & $X$ & $\mathrm{X}$ & $\mathrm{X}$ \\
\hline 14 & Geleia de Umbu & & & & & & & & $\mathrm{X}$ & \\
\hline
\end{tabular}

Fonte: Adaptado de CONAB/DIPAI/SUPAF/SUGOV (2012).

Outro fator a ser destacado é o papel das organizações coletivas formadas dentro das comunidades extrativistas, que servem tanto para comercializar os produtos quanto para organizar e diversificar a produção. A relevância desses atores está na necessidade de agregar valor aos produtos in natura, a fim de aumentar a rentabilidade da produção local. Tendo em vista o exemplo da produção da farinha de mandioca, apresentado no trabalho de Machado, Alves Junior e Freitas (2017) acerca das relações socioprodutivas em reservas extrativistas, que é realizada de forma coletiva, desde o plantio da mandioca até a colheita e o processamento do produto, verifica-se que o mesmo ocorre com a produção dos azeites, geleias, doces e farinhas originários da sociobiodiversidade.

\footnotetext{
${ }^{3}$ Para aprofundamento do tema, ver Marçal (2017) e Telles (2018).
} 


\section{OREVER}

Isso reflete no crescimento, mesmo diante de diversas dificuldades (tais como falta de: conhecimento sobre processos licitatórios, infraestrutura física, capital de giro, entre outros), quando se criam alternativas para uma maior participação de agricultores familiares no mercado do PAA, incluindo desde produtos classificados como de origem manufaturada, que alcançaram uma taxa de crescimento de $3.418,20 \%$, saindo de 11 operações (2009) para 387 (2012), até produtos de origem agroextrativista (com taxa de crescimento de $800,00 \%$ de 2009 a 2012). O crescimento evidenciado entre os anos de 2009 e 2012 nos permite inferir o potencial de evolução tanto de produtos de maior valor agregado quanto de produtos in natura dentro dos mercados institucionais (BRASIL/PNUD, 2012).

No período de 2009 a 2012, foram comercializados 30 produtos de origem animal, possivelmente advindos da pesca artesanal em águas internas (rios, lagos, tanques de piscicultura e outros). Entre eles, 16 eram produtos de origem agroextrativista e 24 produtos de origem manufaturada, ocorrendo um progressivo processo de agregação de valor à matéria-prima. Houve a comercialização de 70 produtos agrícolas e da sociobiodiversidade, fortalecendo a diversidade e a identidade agrícola e nutricional, conforme mostram as Tabelas 3, 4 e 5 .

Ao se analisar as Tabelas 4 e 5, percebe-se que já há uma convergência para uma agregação de valor aos produtos da sociobiodiversidade e, nesse contexto, observa-se na política de incentivo à comercialização do PAA, uma fonte promissora para o desenvolvimento de uma economia para além do fornecimento de produtos in natura, consequentemente, diversificando as fontes de renda das populações envolvidas nesse processo. 


\section{(OREVER R e Estudos Rurais}

Tabela 3: Operações com Produtos da Sociobiodiversidade de Origem Animal no PAA

\begin{tabular}{|c|c|c|c|c|c|}
\hline $\mathbf{N}^{\mathbf{0}}$. & Produtos De Origem animal & 2009 & 2010 & 2011 & 2012 \\
\hline 1 & Acará & 1 & 1 & 1 & 5 \\
\hline 2 & Aracu & 1 & 7 & 4 & 3 \\
\hline 3 & Branquinha & 1 & 7 & 4 & 3 \\
\hline 4 & Pacu & 1 & 12 & 8 & 5 \\
\hline 5 & Tucunaré & 2 & 7 & 2 & 3 \\
\hline 6 & Pescada & 1 & 6 & 4 & 11 \\
\hline 7 & Curimatã & 0 & 17 & 11 & 8 \\
\hline 8 & Piau & 0 & 3 & 2 & 2 \\
\hline 9 & Pirarucu & 0 & 2 & 3 & \\
\hline 10 & Tambaqui curumim & 0 & 3 & 1 & 2 \\
\hline 11 & Tambaqui & 0 & 18 & 61 & 91 \\
\hline 12 & Surubim/pintado & 0 & 1 & 1 & 4 \\
\hline 13 & Bagre & 0 & 1 & 0 & \\
\hline 14 & Pirarara & 0 & 1 & 0 & \\
\hline 15 & Corvina & 0 & 0 & 2 & 1 \\
\hline 15 & Manjuba & 0 & 1 & 1 & \\
\hline 16 & Peixe de pirapitinga & 0 & 0 & 2 & 1 \\
\hline 17 & Pirandira & 0 & 0 & 0 & 1 \\
\hline 18 & Tamuatá & 0 & 0 & 1 & \\
\hline 19 & Matrinchã & 0 & 0 & 0 & 2 \\
\hline 20 & Tainha & 0 & 0 & 1 & 2 \\
\hline 21 & Caranguejo & 0 & 1 & 1 & 1 \\
\hline 22 & Mandubé & 0 & 0 & 0 & 1 \\
\hline 23 & Peixe piranha & 0 & 0 & 0 & 1 \\
\hline 24 & Peixe barba chata & 0 & 0 & 0 & 1 \\
\hline 25 & Corvina & 0 & 0 & 0 & 5 \\
\hline 26 & Peixe serra & 0 & 0 & 0 & 1 \\
\hline 27 & Peixe jeju & 0 & 0 & 0 & 2 \\
\hline 28 & Traíra & 0 & 0 & 0 & 3 \\
\hline 29 & Camarão & 0 & 0 & 0 & 25 \\
\hline 30 & Marisco & 0 & 1 & 1 & 4 \\
\hline & Subtotal & 7 & 89 & 111 & 188 \\
\hline
\end{tabular}

Fonte: CONAB/DIPAI/SUPAF/SUGOV, 2012.

Tabela 4: Operações com Produtos da Sociobiodiversidade de Origem Agroextrativista no PAA

\begin{tabular}{clcccc}
\hline $\mathbf{N}^{\mathbf{0}}$. & Produtos Agroextrativistas & $\mathbf{2 0 0 9}$ & $\mathbf{2 0 1 0}$ & $\mathbf{2 0 1 1}$ & $\mathbf{2 0 1 2}$ \\
\hline 31 & Castanha do Brasil & 3 & 3 & 6 & 6 \\
\hline 32 & Açaí & 0 & 17 & 8 & 36 \\
\hline 33 & Bacaba & 0 & 2 & 3 & 2 \\
\hline 34 & Bacuri & 0 & 0 & 0 & 1 \\
\hline 35 & Murici & 0 & 3 & 1 & 4 \\
\hline 36 & Coco de babaçu & 0 & 4 & 2 & 0 \\
\hline 37 & Castanha de babaçu & 2 & 15 & 15 & 13 \\
\hline 38 & Castanha de cumbaru & 0 & 0 & 0 & 1 \\
\hline 39 & Pequi & 0 & 1 & 1 & 2 \\
\hline 40 & Guariroba & 0 & 1 & 0 & 0 \\
\hline 41 & Cupuaçu & 4 & 37 & 25 & 18 \\
\hline 42 & Pupunha & 1 & 14 & 11 & 10 \\
\hline 43 & Urucum & 1 & 4 & 1 & 1 \\
\hline 44 & Jenipapo & 0 & 1 & & 0 \\
\hline 45 & Tucumã & 0 & 0 & 1 & 0 \\
\hline 46 & Caxi & 0 & 0 & 0 & 5 \\
\hline & Subtotal & $\mathbf{1 1}$ & $\mathbf{1 0 2}$ & $\mathbf{7 4}$ & $\mathbf{9 9}$ \\
\hline
\end{tabular}

Fonte: CONAB/DIPAI/SUPAF/SUGOV, 2012. 
Tabela 5: Operações com Produtos Manufaturados da Sociobiodiversidade no PAA

\begin{tabular}{clcccc}
\hline $\mathbf{N}^{\mathbf{0}}$. & \multicolumn{1}{c}{ Produtos Manufaturados } & $\mathbf{2 0 0 9}$ & $\mathbf{2 0 1 0}$ & $\mathbf{2 0 1 1}$ & $\mathbf{2 0 1 2}$ \\
\hline 47 & Azeite de babaçu & 2 & 20 & 27 & 26 \\
\hline 48 & Cocada de babaçu & 0 & 0 & 1 & 2 \\
\hline 49 & Farinha de babçu & 0 & 0 & 3 & 8 \\
\hline 50 & Flocos de babaçu & 0 & 0 & 3 & 1 \\
\hline 51 & Polpa de cajá & 3 & 27 & 43 & 75 \\
\hline 52 & Polpa de murici & 2 & 19 & 20 & 38 \\
\hline 53 & Polpa de cupuaçu & 3 & 69 & 86 & 65 \\
\hline 54 & Polpa de açaí & 1 & 35 & 44 & 53 \\
\hline 55 & Polpa de bacuri & 0 & 4 & 10 & 16 \\
\hline 56 & Polpa de araçá & 0 & 17 & 16 & 8 \\
\hline 57 & Polpa de buriti & 0 & 12 & 16 & 1 \\
\hline 58 & Polpa de jenipapo & 0 & 1 & 2 & \\
\hline 59 & Polpa de umbu & 0 & 5 & 7 & 12 \\
\hline 60 & Polpa de umbu-cajá & 0 & 0 & 3 & 3 \\
\hline 61 & Polpa de bacaba & 0 & 3 & 4 & 2 \\
\hline 62 & Polpa de buriti & 0 & 3 & 5 & 45 \\
\hline 63 & Polpa de mangaba & 0 & 0 & 0 & 3 \\
\hline 64 & Polpa de cagaita & 0 & 0 & 0 & 1 \\
\hline 65 & Polpa de pequi & 0 & 0 & 0 & 1 \\
\hline 66 & Palmito de pupunha & 0 & 0 & 0 & 6 \\
\hline 67 & Mesocarpo em pó & 0 & 0 & 0 & 2 \\
\hline 68 & Sorvete de babaçu & 0 & 1 & 1 & 2 \\
\hline 69 & Doce de buriti & 0 & 4 & 9 & 15 \\
\hline 70 & Doce de umbu & 0 & 5 & 0 & 2 \\
\hline & & $\mathbf{1 1}$ & $\mathbf{2 2 5}$ & $\mathbf{3 0 0}$ & $\mathbf{3 8 7}$ \\
\hline Fon & Subtotal & A & 0 &
\end{tabular}

Fonte: Adaptado de CONAB/DIPAI/SUPAF/SUGOV, 2012.

Ainda, é importante salientar, corroborando as preocupações elencadas por Costa et al. (2015), que apesar de a agregação de valor ao produto ser uma importante medida do ponto de vista comercial, é necessário superar exigências sanitárias que foram pensadas e estruturadas fora da realidade do agricultor e extrativista familiar, considerando que para promover "adequação sanitária, para além das questões relacionadas à assessoria, a legislação sanitária tem se mostrado incompatível com a realidade dos empreendimentos" (COSTA et al, 2015, p.120).

Se, por um lado, existe um quadro em que é possível agregar valor aos produtos in natura, por outro, é necessário à padronização destes, contudo, ainda há uma dissonância entre a padronização promovida pela legislação e a realidade da agricultura familiar. Desse modo, de acordo com Costa et. al. (2015), a aplicação destas normas vigentes proporciona uma concentração de mercado, visto que as grandes empresas agroalimentares têm maior estrutura para atender as exigências, tendo inclusive um custo menor em seu atendimento, sobretudo as de produtos com maior valor agregado. Logo, 


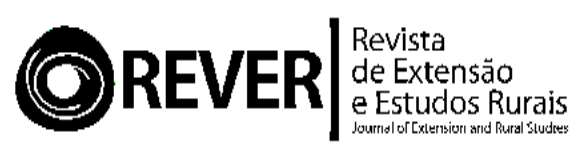

são criadas condições que atrapalham a entrada de novos empreendimentos de cunho familiar de pequeno porte, e a legislação federal que incide sobre agroindústrias efetivamente tem excluído a realidade do setor artesanal de produtos perecíveis.

Outros fatores que afetam a comercialização de produtos do PNAE e PAA são os efeitos provocados pela sazonalidade, à redução de custos unitários de produção (que impactam na formação do preço de venda) em diversas regiões e o papel exercido pelo “atravessador" (intermediário entre o produtor e o mercado). Associadas a isso, verificase a imposição das legislações de conformidade sanitária para os produtos e a sempre persistente ausência ou insuficiência dos serviços de Assistência Técnica em Extensão Rural (ATER).

\section{Produtos da Sociobiodiversidade no PNAE}

As normativas de execução da Lei $\mathrm{n}^{\mathrm{o}}$ 11.947/2009, que rege o PNAE e a participação de produtos da agricultura familiar no programa, são bem definidas quanto à obrigatoriedade de aquisição de produtos para a merenda escolar regionalizada. Essa obrigatoriedade está prevista no art. 14 da respectiva lei. Do total dos recursos financeiros repassados pelo FNDE para o PNAE, no mínimo 30\% (trinta por cento) devem ser utilizados na aquisição de gêneros alimentícios advindos diretamente da agricultura familiar, de Associações ou Cooperativas.

A mesma lei trata dos procedimentos quanto à "forma de aquisição", em seu art. $14, \S 1^{\circ}$. A aquisição de que trata este artigo poderá ser realizada dispensando-se o procedimento licitatório, desde que os preços sejam compatíveis com os vigentes no mercado local, observando-se os princípios inscritos no art. 37 da Constituição Federal, e desde que os alimentos atendam às exigências do controle de qualidade estabelecidas pelas normas que regulamentam a matéria.

Mesmo assim, a ampliação do volume de produtos da Sociobiodiversidade a serem comercializados no PNAE ainda é um desafio a ser superado. Na realização das Chamadas Públicas, quanto à execução dos Diagnósticos das Unidades de Produção Familiar (UPFs), não é sequer realizado um levantamento específico para identificação desses produtos.

Os recursos do PNAE são gerenciados pelo Fundo Nacional de Desenvolvimento da Educação (FNDE/MEC) e destinados à aquisição de produtos regionalizados para merenda escolar, agricultura familiar e extrativista. Considerando a aplicação do valor total, as operações de compras do PNAE podem ser divididas da seguinte forma: $70 \%$ de 


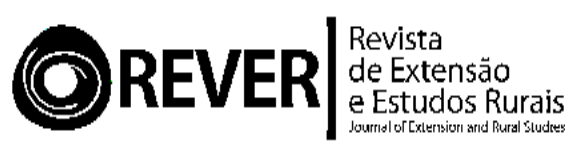

produtos industrializados (Edital de Pregão Presencial); e 30\% de produtos da agricultura familiar (mínimo obrigatório, por Edital de Chamada Pública).

No PNAE, o valor máximo é de R\$20.000,00 por Declaração de Aptidão ao Pronaf - DAP Física do produtor individual, DAP Jurídica ou através de Associação ou Cooperativa. O Edital de Chamada Pública é o instrumento de operacionalização de compra dos produtos agrícolas.

O Quadro 1 apresenta uma tipologia dos produtos comercializados no PNAE, segundo levantamento qualitativo realizado pelo MDA (2012, p. 43), sendo categorizados da seguinte forma: Hortifrutigranjeiros, Grãos, Processados e Carne. A categoria Processados abrange a subcategoria Panificados, e foram enquadrados na categoria Grãos: feijão, milho, café, amendoim, soja, arroz e ervilha.

Ainda no mesmo levantamento, observou-se que, entre uma relação de 8.056 produtos, as categorias mais comercializadas distribuíam-se na seguinte ordem: Hortifrutigranjeiros, com 6.762 solicitações; Processados, com 835, sendo que destes 86 são produtos Panificados; Grãos, com 368 solicitações; e Carnes, com 91.

Os Hortifrutigranjeiros abrangeram cerca de 100 produtos diferentes e estiveram entre os mais demandados nas chamadas públicas. Dentro dessa categoria, não houve qualquer distinção entre produtos in natura, processados e manufaturados, para efeito de análise, tampouco maior compreensão se provenientes de beneficiários da agricultura familiar (Quadro 1). 
Quadro 1: Tipologia de Produtos Comercializados no PNAE

\begin{tabular}{|c|c|}
\hline Categorias & Produtos / Alimentos \\
\hline $\begin{array}{c}\text { Processados } \\
\text { (manufaturados) }\end{array}$ & $\begin{array}{l}\text { Bebida láctea, iogurte, leite (pó, integral, fluído), manteiga, queijos, polpa de } \\
\text { frutas, doces de frutas, rapadura, doce-de-leite, beiju, farinha (mandioca, milho, } \\
\text { coco de babaçu, soja, centeio), pasta de alho, tapioca, cocada, cominho, cravo, } \\
\text { canela (em pau e pó), tempero pronto, mel de abelha, flocos de milho, fubá de } \\
\text { milho, carimã, geleia de frutas, leite de coco, molho e extrato de tomate, bolo, } \\
\text { azeite, achocolatado em pó, mistura de mingau, broa de milho, colorau, biscoito, } \\
\text { creme de milho, açafrão, açúcar mascavo, aveia, queijo coalho, pão, nata natural, } \\
\text { rosca, macarrão, colorau, frutas passa, massa caseira, água de coco, açúcar, milho } \\
\text { verde em conserva, óleo de soja, sal refinado, suco de frutas, proteína de soja, } \\
\text { biscoito de polvilho, melado de cana, requeijão, mariola, almondega, quibe e } \\
\text { croquete de peixe, picolé de frutas, cuca, pepino conserva, salsicha, mortadela, } \\
\text { chimier, creme de leite, linguiça, pêssego em calda, pastel, polvilho, farelo de } \\
\text { trigo, vinagre, cogumelo, barra de cereal, coco ralado, polvilho, sequilho, corante, } \\
\text { massa de macaxeira, azeite, cuscuz de milho, cuscuz de arroz. }\end{array}$ \\
\hline Panificados & Bolos, broa de milho, biscoitos, pães, rosca, biscoito de polvilho e cuca. \\
\hline Carnes & $\begin{array}{l}\text { Aves (inteiro ou cortes), bovino (filé, cortes, moída), pescado (filé, moído, } \\
\text { inteiro, posta), charque, ovino (inteiro ou cortes) e suíno (inteiro ou cortes). }\end{array}$ \\
\hline Hortifrutigranjeiros & $\begin{array}{l}\text { Abacate, abacaxi, abóbora, abobrinha, açafrão, acelga, acerola, agrião, aipim, } \\
\text { alcachofra, alecrim, alface, alho, almeirão, ameixa, amendoim, amora, arroz } \\
\text { (normal, integral e parboilizado), atemoia, aveia, banana, batata, batata-baroa, } \\
\text { batata-doce, beterraba, berinjela, brócolis, caju, caqui, cará, carambola, cariru, } \\
\text { catalonha, cebola, cebolinha, cenoura, cheiro-verde, chicória, chuchu, coco } \\
\text { verde, coentro, cogumelo, couve, couve-flor, ervilha, escarola, espinafre, fava, } \\
\text { feijão (branco, carioquinha, de corda, fradinho, macassar, mulatinho, preto, } \\
\text { verde e vermelho), framboesa, gengibre, goiaba, graviola, groselha, hortelã, } \\
\text { inhame, jabuticaba, jaca, jerimum, jiló, kiwi, laranja (lima e pera), lentilha, lichia, } \\
\text { lima da pérsia, limão, louro, maçã, mandioca, mandioquinha, manga, } \\
\text { manjericão, maracujá, maxixe, melancia, melão, mexerica, milho amarelo, milho } \\
\text { branco, milho de pipoca, milho-verde, milho xerém, moranga, morango, } \\
\text { mostarda, nabo, ovos de codorna, ovos de galinha, palmito, pepino, pera, } \\
\text { pimentão, pinha, quiabo, rabanete, repolho, rúcula, salsa, salsão, salsinha, soja, } \\
\text { tangerina, tomate, umbu, uva, vagem e vinagreira. }\end{array}$ \\
\hline
\end{tabular}

Fonte: Adaptado de CCOM/DGRAV/SAF/MDA, 2012, p. 43

A eficiência da operacionalização de compras, através de Edital de Chamada Pública para cumprimento das exigências do PNAE, ainda é difícil e controversa. Como indicados no quadro anterior, apesar da significativa diversidade das categorias de produtos comercializados, existem diferenças entre o que é demandado para compra e os produtos realmente adquiridos. De acordo com Triches (2018, p. 249):

verificando os produtos reivindicados e os realmente comprados, foi possível perceber que, no geral, as prefeituras demandaram alguns tipos de alimentos, mas compraram outros. Essas ocorrências podem ser explicadas ao se considerar que a produção de frutas, legumes e verduras e produtos minimamente processados já são culturas estabelecidas pelos agricultores familiares e, portanto, mais passíveis de oferta. Além disso, não necessitam de maiores adequações aos padrões exigidos de certificação e inspeção, como acontece com produtos mais processados e de origem animal. 


\section{OREVER|}

A ampliação da presença de produtos da agricultura familiar e da sociobiodiversidade no PNAE depende de adequações de diversas naturezas, como: adequação às exigências sanitárias, aos padrões de embalagem e qualidade, à regularidade para cumprimento dos contratos de venda, entre outras. É importante verificar quais grupos de produtos se fazem mais presentes, em maior ou menor volume nas aquisições da agricultura familiar, pois alguns produtos atendem a critérios destacados anteriormente. Essa situação é corroborada por Triches e Silvestri (2018) ${ }^{4}$ :

quando fazem referência ao grupo que se destaca na comercialização, caso dos panificados, pois, nas chamadas públicas, foram solicitados somente $3,03 \%$ desses produtos, porém, ao analisar o que realmente foi comprado, verificou-se um porcentual de $30,34 \%$. Supõe-se que esse grupo esteja ocupando cada vez mais espaço nas aquisições de agricultores familiares, por terem maior valor agregado, se comparado ao grupo de frutas e hortaliças, gerando mais renda, além de não dependerem de condições climáticas para serem produzidos. (TRICHES e SILVESTRI, 2018, p. 250)

\section{Instrumentos de Registro de Informações para Gestão de Resultados}

Na execução do PNPSB, ainda não é possível identificar os produtos da sociobiodiversidade adquiridos para alimentação escolar. A proposta de identificação, através de um formulário a ser inserido em Contratos e/ou Projetos de compra de produtos da sociobiodiversidade, pode ser viável e poderá suprir uma "falha" na execução da gestão operacional e administrativa do programa PNAE em todo o Brasil, como problematizado ao longo deste artigo.

A proposta de formulários de Identificação de Produtos da Sociobiodiversidade comercializados no PNAE organiza-se com a seguinte estrutura: Cabeçalho, o qual contém as informações pessoais do produtor rural (Quadro 2); e Formulário de produtos da Sociobiodiversidade, contendo uma coluna destinada aos Produtos, outra à Comercialização e outra aos Indicadores de Produção (Quadro 3).

\footnotetext{
4 Adequação das Chamadas Públicas para Aquisição de Produtos da Agricultura Familiar para a Alimentação Escolar. Chamadas Públicas (CPs), realizadas por prefeituras municipais do estado do Paraná, foram analisadas quanto a sua adequação em relação ao público que pretendem alcançar e quanto à consecução de seu objetivo no que se refere à compra efetiva quando comparada aos produtos que solicita.
} 


\section{OREVER

Quadro 2: Cabeçalho da proposta de Formulário para a identificação de Produtos da Sociobiodiversidade no âmbito do PNAE

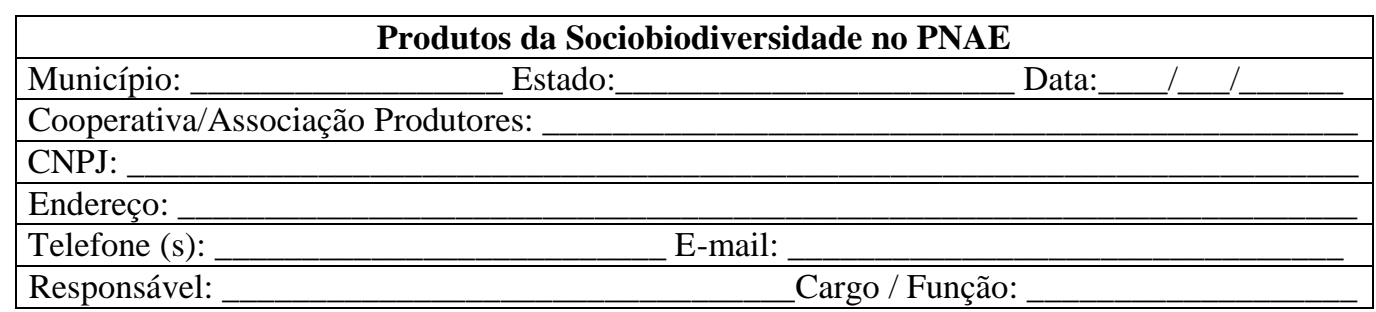

Fonte: Adaptado de DGRAV/SAF/MDA, 2012.

Em relação ao formulário de produtos da sociobiodiversidade comercializados no PNAE, a coluna Produtos visa a identificar os produtos agrícolas e agroextrativistas presentes no mapeamento da vocação agrícola municipal ou territorial, confrontando-os com aqueles previstos nos Cardápios Nutricionais das Escolas Municipais ou Estaduais e dos demais usuários do PNAE. Já a coluna Comercialização, tem a finalidade de caracterizar se o produto foi comercializado na forma in natura (IN) ou industrializado (IND), enquanto as colunas destinadas aos Indicadores de Produção, nomeadas no formulário como Produto Comercializado Ano 1 e Produto Comercializado Ano 2, objetivam obter informações sobre a quantidade e o valor do produto comercializado por ano (Quadro 3).

De maneira adjunta a esse Formulário, também existe uma área destinada a identificar o comprador, a quantidade e o valor total de compra por entidade Operadora no âmbito do PNAE (Quadro 4), assim como um espaço assinalado para a identificação de Empreendimento Coletivo e quantidade de Beneficiários na Comercialização de Produtos da Sociobiodiversidade, como mostra o Quadro 5. 


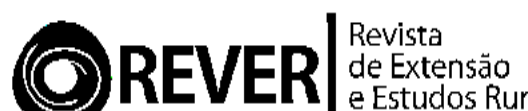 \\ e Estudos Rurais}

Quadro 3: Identificação dos Produtos da Sociobiodiversidade comprados no PNAE

\begin{tabular}{|c|c|c|c|c|c|c|}
\hline \multirow[t]{2}{*}{ Produtos } & \multicolumn{2}{|c|}{ Comercialização* } & \multicolumn{2}{|c|}{$\begin{array}{c}\text { Produto } \\
\text { Comercializado Ano } 1\end{array}$} & \multicolumn{2}{|c|}{$\begin{array}{c}\text { Produto } \\
\text { Comercializado Ano } 2\end{array}$} \\
\hline & IN & IND. & $\begin{array}{l}\text { Quant. } \\
\text { (Kg.) }\end{array}$ & $\begin{array}{l}\text { Valor } \\
(\mathbf{R} \$)\end{array}$ & $\begin{array}{c}\text { Quant. } \\
\text { (Kg.) }\end{array}$ & $\begin{array}{l}\text { Valor } \\
(\mathbf{R} \$)\end{array}$ \\
\hline \multicolumn{7}{|l|}{ Araçá } \\
\hline \multicolumn{7}{|l|}{ Babaçu } \\
\hline \multicolumn{7}{|l|}{ Bacuri } \\
\hline \multicolumn{7}{|l|}{ Baru } \\
\hline \multicolumn{7}{|l|}{ Buriti } \\
\hline \multicolumn{7}{|l|}{ Açaí } \\
\hline \multicolumn{7}{|l|}{ Castanha de Caju } \\
\hline \multicolumn{7}{|c|}{ Castanha-do- Brasil } \\
\hline \multicolumn{7}{|l|}{ Cupuaçu } \\
\hline \multicolumn{7}{|l|}{ Erva mate } \\
\hline \multicolumn{7}{|l|}{ Guaraná } \\
\hline \multicolumn{7}{|l|}{ Jenipapo } \\
\hline \multicolumn{7}{|l|}{ Juçara (palmito) } \\
\hline \multicolumn{7}{|l|}{ Licuri } \\
\hline \multicolumn{7}{|l|}{ Mangaba } \\
\hline \multicolumn{7}{|l|}{ Murici } \\
\hline \multicolumn{7}{|l|}{ Pequi } \\
\hline \multicolumn{7}{|l|}{ Pinhão } \\
\hline \multicolumn{7}{|l|}{ Piquiá } \\
\hline \multicolumn{7}{|l|}{ Pupunha } \\
\hline \multicolumn{7}{|l|}{ Tucumã } \\
\hline \multicolumn{7}{|l|}{ Umbu } \\
\hline Outros & & & & & & \\
\hline
\end{tabular}

Fonte: Adaptado de DGRAV/SAF/MDA, 2012.

Quadro 4: Identificar o Comprador, a Quantidade e o Valor Total por Entidade Operadora do PNAE

\begin{tabular}{l|c|c|c|c|c|c|c|c}
\hline \multirow{2}{*}{ Instituição / Entidade } & \multicolumn{2}{|c|}{2009} & \multicolumn{2}{c|}{$\mathbf{2 0 1 0}$} & \multicolumn{2}{c|}{$\mathbf{2 0 1 1}$} & \multicolumn{2}{c}{$\mathbf{2 0 1 2}$} \\
\cline { 2 - 8 } & $\begin{array}{c}\text { Quant. } \\
\text { (Kg.) }\end{array}$ & $\begin{array}{c}\text { Valor } \\
\text { (R\$) }\end{array}$ & $\begin{array}{c}\text { Quant. } \\
\text { (Kg.) }\end{array}$ & $\begin{array}{c}\text { Valor } \\
\text { (R\$) }\end{array}$ & $\begin{array}{c}\text { Quant. } \\
\text { (Kg.) }\end{array}$ & $\begin{array}{c}\text { Valor } \\
\text { (R\$) }\end{array}$ & $\begin{array}{c}\text { Quant. } \\
\text { (Kg.) }\end{array}$ & $\begin{array}{c}\text { Valor } \\
\text { (R\$) }\end{array}$ \\
\hline Prefeitura Municipal: & & & & & & & & \\
\hline Estado (Entidade): & & & & & & & & \\
\hline
\end{tabular}

Fonte: Adaptado de DGRAV/SAF/MDA, 2012.

Quadro 5: Identificação de Empreendimento Coletivo e Quantidade de Beneficiários na Comercialização de Produtos da Sociobiodiversidade (PNAE)

\begin{tabular}{|c|c|c|c|c|c|c|c|c|}
\hline \multirow[t]{3}{*}{ Instituição / Entidade } & \multicolumn{8}{|c|}{$\mathbf{N}^{\circ}$. Beneficiários } \\
\hline & \multicolumn{2}{|c|}{2009} & \multicolumn{2}{|c|}{2010} & \multicolumn{2}{|c|}{2011} & \multicolumn{2}{|c|}{2012} \\
\hline & Ass. & Coop. & Ass. & Coop. & Ass. & Coop. & Ass. & Coop. \\
\hline Cooperativa / Associação: & & & & & & & & \\
\hline
\end{tabular}

Fonte: Adaptado de DGRAV/SAF/MDA, 2012.

A importância de estabelecer formulários quantitativos e qualitativos para monitorar e acompanhar as operações de venda no âmbito do PNAE reflete no objetivo 


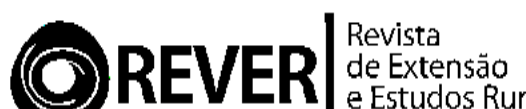 e Estudos Rurais}

de contribuir para o aumento das atividades de gestão administrativa e operacional do programa. O conhecimento da evolução histórica e particularizada sobre as operações envolvendo a comercialização de produtos in natura, industrializados, semiprocessados, entre outros, deve contribuir para que as Entidades Executoras (EEx.) possam operar buscando maior eficiência, eficácia e efetividade do programa.

Apesar de a contribuição acima mencionada ser importante, existem outros aspectos complementares que são fundamentais, como a formação e a capacitação de produtores, associados e cooperados em atividades relacionadas à gestão, ao cooperativismo e à agroindustrialização. E, nesse aspecto, as políticas públicas de assistência técnica e extensão rural e o acompanhamento regular adequado da gestão associativista ou cooperativista podem ser determinantes.

\section{Mercado de Feiras e Eventos: Promoção de Produtos e Sociobiodiversidade}

O uso de estratégias comerciais para atuação de produtores da agricultura familiar é uma importante iniciativa adotada por órgãos federais, estaduais e municipais, que realizam (ou oportunizam), com alguma periodicidade, a participação em feiras agrícolas ou eventos de promoção de produtos.

Nesses ambientes, a identificação de clientes efetivos e potenciais contatados representa uma oportunidade de ampliação da comercialização de produtos da agricultura familiar. Quando da participação de produtos agrícolas e da sociobiodiversidade nesses eventos, é importante coletar informações sobre os tipos de clientes (varejistas ou atacadistas), quais produtos e as quantidades compradas, além do número de produtores beneficiados no âmbito do PNAE (Quadro 6).

Quadro 6: Formulário para a identificação de Clientes Efetivos e Potenciais em Feiras e Eventos

\begin{tabular}{l|c|c|c|c|c}
\hline \multirow{2}{*}{ Ano (s) } & $\begin{array}{c}\text { Cliente (s) } \\
\text { Varejo/ Atacado }\end{array}$ & Produto (s) & Quantidade (s) & $\begin{array}{c}\text { Valor (R\$) } \\
\text { Vendas }\end{array}$ & $\begin{array}{c}\text { No. Produtores } \\
\text { Beneficiados }\end{array}$ \\
\hline \multirow{3}{*}{$\ldots . . .}$. & & & & & \\
\cline { 2 - 6 } & & & & \\
\hline \multirow{3}{*}{$\cdots . . . .}$. & & & & & \\
\cline { 2 - 6 } & & & & \\
\cline { 2 - 6 } & & & & \\
\cline { 2 - 6 } & & & & \\
\hline
\end{tabular}

Fonte: Adaptado de DGRAV/SAF/MDA, 2012. 


\section{OREVER}

Com relação à gestão administrativa e operacional do PNAE, o FNDE é o responsável pelo repasse financeiro em caráter complementar, pela normatização, coordenação, acompanhamento, monitoramento e fiscalização da execução do programa, além da avaliação da sua efetividade e eficácia. Para que isso se torne realidade em suas diferentes características, é importante conhecer aquilo que acontece na rotina de execução do programa de maneira mais particularizada.

E, nesse sentido, a carência de informações qualificadas quanto à plena execução do programa ainda é uma realidade. Para tanto, a proposta de apresentar esses “formulários-padrão" pode contribuir para avançar as operações de gestão por parte das entidades executoras, buscando:

i) caracterizar e definir melhor qual (ou quais) informação quantitativa é relevante para avaliação do programa ao longo dos anos;

ii) aplicar um "questionário-padrão" para acompanhamento, monitoramento e levantamento de informações nos órgãos de origem da ação, do programa ou da atividade;

iii) estabelecer como obrigatório o repasse de informações, para alimentação periódica de uma planilha "quantitativa única", modelada para apuração de indicadores de resultados do programa, que assegure a cobertura do período de efetivação das políticas.

\section{Considerações Finais}

Conforme destacado por Triches e Silvestri (2018, p. 255), existe dificuldade considerável em se levantar dados e informações acerca da aquisição de gêneros alimentícios para os mercados institucionais, uma vez que não há uma base de dados unificada e a maioria das prefeituras não divulga, por meio eletrônico de fácil acesso (como seus sites), as suas chamadas. Isso se reflete ainda no baixo grau de conhecimento e publicidade, o que impede que os próprios agricultores familiares acessem as chamadas, sendo um dos fatores que limitam sua participação.

Ainda, Camargo et al. (2012, p. 13), ao abordarem a situação da agricultura familiar no estado de São Paulo, como na maior parte do Brasil, verificam que a agricultura familiar enfrenta dificuldades como a descapitalização, a falta ou a insuficiência dos serviços de Assistência técnica e Extensão rural (ATER) e a pouca ou nenhuma infraestrutura instalada na propriedade. Soma-se a esses entraves a dificuldade dos agricultores em se organizarem em cooperativas ou associações, predominando a preferência pelo trabalho individualizado. 


\section{OREVER}

Para a gestão organizacional, institucional e operacional do PNAE avançar e cumprir a determinação legal de aplicação de aquisição de no mínimo $30 \%$ de produtos agrícolas e da sociobiodiversidade (podendo alcançar até $50 \%$ ou mais) é fundamental conhecer, quantificar e monitorar quais são os produtos adquiridos e quais as dificuldades envolvidas no aumento da participação desses produtos nas Chamadas Públicas. Para isso, a proposta de adoção e aplicação dos formulários quantitativos apresentados nesse breve artigo parece ter consistência e viabilidade, considerando a eficiência de gestão do programa.

Apesar da importante dinâmica de alcance do mercado institucional, possibilitada pelo PAA e PNAE, ainda permanecem problemas estruturais na difícil realidade da agricultura familiar, como: desarticulação do sistema oficial de extensão rural; problemas fundiários; fragilidade organizacional dos agricultores, principalmente em razão do uso de modelos de gestões organizacionais pouco adaptados às suas relações sociais; extensionistas com forte intervenção tecnicista e produtivista adeptos do modelo de agricultura empresarial; e, ainda, o fato de a pesquisa agropecuária ser voltada aos aspectos tecnológicos da produção.

O PAA e o PNAE são estratégias de políticas públicas de desenvolvimento rural, nas quais o Estado e os Agricultores Familiares são os atores da relação central. Um aspecto importante é que essas políticas foram concebidas fora dos esquemas tradicionais de industrialização das cadeias alimentares e, como princípio básico, buscam viabilizar novos canais de comercialização no mercado institucional da alimentação escolar.

A identificação detalhada dos indicadores da participação de produtos da Sociobiodiversidade no PNAE (valor e quantidade de produtos comercializados, número de produtores participantes, entidades associativo-cooperativas envolvidas, preço pago, período de realização, etc.) é uma tarefa difícil na atual forma de execução do programa. Ou seja, ainda é inviável a realização dessas apurações visando a garantir uma ampla cobertura das principais ações e atividades que sirvam de indicadores quantitativos (e até qualitativos) para fundamentar uma revisão consistente na gestão administrativa e operacional do PNAE relacionada à participação dos produtos da Sociobiodiversidade.

Como o PNAE possui articulação e interface de execução com outros agentes institucionais, o trabalho de articulação para coletar, tabular e sistematizar as informações geradas em outros ministérios e órgãos executores deve considerar que os indicadores dependem da realização efetiva das safras agrícolas de culturas perenes e temporárias, 


\section{OREVER/|}

das safras do agroextrativismo, dos cardápios escolares e também dos recursos disponíveis para a efetivação anual do PNAE e PAA.

É importante compreender que, ao contrário de outras cadeias produtivas, em que existe a predominância de apenas um produto, na sociobiodiversidade, existem várias cadeias produtivas, com abrangência municipal, territorial, regional e nacional, e as atividades são realizadas em parceria com as Câmaras Técnicas Estaduais da Sociobiodiversidade (ou Grupos de Trabalho), vinculadas a um planejamento orçamentário previsto e efetivamente realizado nos municípios e estados de todo o país.

Foi constatado que diversas informações sobre projetos e programas do PNPSB ainda não possuem dados quantificados, em função da real necessidade de obtenção de informações consolidadas, para avaliação e desempenho do plano. Em particular, faltam dados acerca da identificação de produtos da Sociobiodiversidade nas vendas de programas do mercado institucional, dificultando estabelecer padrões de mensuração quantitativa para o Programa de Aquisição de Alimentos (PAA) e para o Programa Nacional de Aquisição de Merenda Escolar (PNAE), ou seja, se mostra imperativo a adoção e a aplicação de instrumentos (formulários, questionários, etc.) para registrar e quantificar a presença de importantes produtos oriundos das comunidades agroextrativistas fornecedoras desses mercados.

É importante salientar, conforme destacado por Gomes e Cesar (2018), que a criação de políticas públicas de acesso a mercados deve ser acompanhada de ações que promovam um ambiente onde os agricultores (e extrativistas) familiares possam ser capazes de agregar valor aos seus produtos, sendo o cooperativismo e o associativismo uma das formas mais viáveis para a organização coletiva e produtiva da agricultura familiar.

Em síntese, evidencia-se que os programas PAA e PNAE ainda carecem de instrumentos técnicos de acompanhamento, monitoramento e registro de dados quantitativos de desempenho da execução operacional em suas múltiplas dimensões, para efeito prático de avaliação dos resultados alcançados junto a fornecedores da agricultura familiar, e essa ausência de "informações qualificadas/quantificadas" compromete a eficiência e eficácia da execução de outros Planos de ação, caso do PNPSB.

\section{Referências Bibliográficas}

BACCARIN, J. G. et al. Alimentação escolar e agricultura familiar: alcance e dificuldades para implantação do Artigo 14 da Lei 11.947/2009 no Estado de São Paulo. 


\section{OREVER/|}

In: Congresso da Sociedade Brasileira de Economia, Administração e Sociologia Rural, 2011, Belo Horizonte. Belo Horizonte: SOBER, 2011. p.1-20.

BRASIL. CASA CIVIL, Lei n 11.346/2006 (Sistema Nacional de Segurança Alimentar e Nutricional - SISAN). Disponível em: http://www.planalto.gov.br/ccivil_03/_ato20042006/2006/lei/111346.htm. Acesso em: 01 de julho de 2017.

BRASIL. CASA CIVIL, Decreto n ${ }^{\circ}$ 7.272, de 25 de agosto de 2010. Política Nacional de Segurança Alimentar e Nutricional - PNSAN. Disponível em http://www.planalto.gov.br/ccivil_03/_ato2007-2010/2010/decreto/d7272.htm. Acesso em: 01 de julho de 2017.

BRASIL. MDA. Censo Agropecuário 2006 (Agricultura familiar). Disponível em: http://www.mda.gov.br/sitemda/publicacoes/censo-agropecu\%C3\%A1rio-2006. Acesso em: 01 de julho de 2017.

BRASIL. MMA. Sociobiodiversidade - Políticas Públicas Articuladas - Portaria Interministerial MDA/MDS/MMA $\mathrm{n}^{\mathrm{o}}$ 239, de 21/07/09. Disponível em: http://www.mma.gov.br/desenvolvimento-rural/sociobiodiversidade/comissao-nacionalde-agroecologia-e-producao-organica/itemlist/category/76-sociobiodiversidade. Acesso em: 01 de julho de 2017.

BRASIL. CÂMARA DOS DEPUTADOS. Lei da Agricultura Familiar - Lei $\mathrm{n}^{\circ}$. $11.326 / 2006$

Disponível em http://www2.camara.leg.br/legin/fed/lei/2006/lei-11326-24-julho-2006544830-norma-pl.html. Acesso em: 30 de junho de 2017.

BRASIL. FNDE. Programa Nacional de Alimentação Escolar (PNAE - Lei $\mathrm{n}^{\circ}$ 11.947/2009), Lei da Merenda Escolar, Lei de Alimentação Escolar, Lei do Programa Dinheiro Direto na Escola - FNDELegis. Disponível em https://www.fnde.gov.br/fndelegis/action/UrlPublicasAction.php?acao=getAtoPublico\& sgl_tipo=LEI\&num_ato $=00011947 \&$ seq_ato $=000 \& v 1 r \_a n o=2009 \& s g 1 \_$orgao $=N I$.

Acesso em: 30 de junho de 2017.

BRASIL. CONAB. Programa de Aquisição de Alimentos - PAA: Legislação Básica, Brasília, julho de 2010. Disponível em http://www.conab.gov.br/conteudos.php?a=1125. Acesso em: 01 de julho de 2017.

BRASIL. Companhia Nacional de Abastecimento - CONAB. Planilhas de Resultados do Programa de Aquisição de Alimentos - PAA, 2009 a 2012. CONAB/MAPA, 2012. AB. Planilhas de Resultados da Política de Garantia de Preços Mínimos para a Biodiversidade - PAA, 2011/2012. CONAB/MAPA, 2012.

BRASIL. Ministério do Desenvolvimento Agrário - MDA. Balanço Geral do Departamento de Geração de Renda e Agregação de Valor - 2009-2011.

BRASIL. Ministério do Desenvolvimento Agrário - MDA. Relatório parcial sobre o PNAE. Coordenadoria de Comercialização - CCOM/DGRAV/SAF/MDA (Doc. Interno). Brasília - DF, 2012. 


\section{OREVER|}

BRASIL. MDA. Plano Nacional da Cadeia de Produtos da Sociobiodiversidade (PNPSB). Disponível em: www.mda.gov.br/sitemda/.../sitemda/.../Plano_Nacional_da_Sociobiodiver.... e http://www.mma.gov.br/perguntasfrequentes?catid=17. Acesso em 01 de julho de 2017. BRASIL. PORTAL EMBRAPA.

https://www.embrapa.br/codigo-florestal/area-de-reserva-legal-arl/modulo-fiscal. Acesso em 05/04/2019.

BRASIL. Ministério do Meio Ambiente (MMA). http://www.mma.gov.br/desenvolvimento-rural/sociobiodiversidade . Acesso em $05 / 04 / 19$

BRASIL. Ministério do Desenvolvimento Agrário (MDA). http://www.mda.gov.br/sitemda/secretaria/saf-biodiv/sociobiodiversidade-brasileira.

Acesso em 05/04/19.

BRASIL. MMA. Arranjos produtivos locais : APLs de produtos da sociobiodiversidade I Ministério do Meio Ambiente - Brasília, DF:, 2017. Disponível: http://www.mma.gov.br/publicacoes/desenvolvimento-rural/category/75sociobiodiversidade.html . Acesso em 05/04/19.

BRASIL. CONAB. Companhia Nacional de Abastecimento. Programa de Aquisição de Alimentos - PAA: Legislação Básica / Companhia Nacional de Abastecimento. Brasília: Conab, 2018.

BRASIL. CONAB. Companhia Nacional de Abastecimento. Compêndio de Estudos Conab / Companhia Nacional de Abastecimento. - v. 1 (2016). - Brasília: Conab, 2016.

BRASIL AGROECOLÓGICO: Plano Nacional de Agroecologia e Produção Orgânica PLANAPO: 2016-2019 / Câmara Interministerial de Agroecologia e Produção Orgânica. - Brasília, DF: Ministério do Desenvolvimento Agrário, 2016.

BRASIL. Ministério da Agricultura, Pecuária e Abastecimento - MAPA. Produtos orgânicos: sistemas participativos de garantia /Ministério da Agricultura, Pecuária e Abastecimento, Secretaria de Desenvolvimento Agropecuário e Cooperativismo Brasília: MAPA/ACS 2012.

BRASIL. Ministério do Desenvolvimento Agrário - MDA, Secretaria da Agricultura Familiar, Instituto Via Pública Projeto Nutre SP: análise da inclusão da agricultura familiar na alimentação escolar no estado de São Paulo /Maria Amélia Jundurian Corá; Walter Belik, organizadores --- São Paulo: Instituto Via Pública, 2012.

CAMARGO, R. A. L. de. BACCARIN, J. G. SILVA, D. B. P. da. O Papel Do Programa de Aquisição de Alimentos (PAA) e do Programa Nacional de Alimentação Escolar (PNAE) no Fortalecimento da Agricultura Familiar e Promoção da Segurança Alimentar. UNESP, 2012.

COSTA, B. A. L., JUNIOR, P. C. G. A., SILVA, M. G. da. As Cooperativas de Agricultura Familiar e o Mercado de Compras Governamentais em Minas Gerais. Revista 


\section{OREVER|}

de Economia e Sociologia Rural (RESR/SOBER), Piracicaba - SP, Vol. 53, nº 01, p. 109126, Jan/Mar 2015 - abril de 2015.

DOMINGUES, M. S.; BERMANN, C. O Arco de Desflorestamento na Amazônia: da pecuária à soja. Ambiente \& Sociedade - São Paulo v. XV, nº. 2- p. 1 -22 - Mai.- Ago. 2012

FREITAS, Alair Ferreira de; FREITAS, A. F. Interações entre organizações coletivas na promoção do desenvolvimento local. Interações (UCDB), v. 14, p. 177-188, 2013.

GIL, A. C. Como elaborar projetos de pesquisa. 4. ed. São Paulo: Atlas, 2008

GOMES, Eulália de Lima; CEZAR, Layon Carlos. O papel das cooperativas da agricultura familiar no desenvolvimento de políticas públicas. Revista de Extensão e Estudos Rurais, Viçosa, MG, v. 7, n. 1, p. 166-186, jul. 2018. ISSN 2359-5116. Disponível em: <https://periodicos.ufv.br/ojs/rever/article/view/3375>. Acesso em: 11 jun. 2019. doi:https://doi.org/10.18540/rever112018166-186

GRISA, C.; SCHINEIDER, S. Três gerações de políticas públicas para agricultura familiar e interação entre Estado e Sociedade Civil no Brasil. RESR, v. 52, n. Supl. 1, p. S125-S146, 2014.

MACHADO, F; ALVES JUNIOR, A; FREITAS, A. Análise das relações socioprodutivas na Resex Baixo Juruá a partir da sociologia econômica. Espacios, v38, 2017.

MARÇAL. K. O lado invisível da economia. São Paulo: Editora Alaúde, 2017.

MOTA, D. M. et al. As catadoras de mangaba no Programa de Aquisição de AlimentosPAA: um estudo de caso em Sergipe. Revista de Economia e Sociologia Rural, v.52, n.3, p. 449-470, 2014.

PICCIN, M. B. GIZ. Estudo sobre Criação de Espaços de Coordenação e Articulação Estaduais de Comercialização - Relatório técnico contendo proposta de criação de redes e instâncias de comercialização e abastecimento nos Estados do Acre, Amazonas, Amapá e Pará. Secretaria Especial de Agricultura Familiar e Desenvolvimento Agrário SEAD/MDSA, 2016.

PNUD - Programa das Nações Unidas para o Desenvolvimento. Projeto PNUD/BRA/11/009. Contrato No 2012/000218, Termo de Referência No 136547. Brasília, 2011. Produto 6: Relatório técnico de avaliação do Programa de Aquisição de Alimentos (PAA) e do Programa Nacional de Alimentação Escolar (PNAE) relativo aos produtos da sociobiodiversidade e Balanço parcial das atividades do Plano Nacional da Sociobiodiversidade em 2012.

SILVA, José Graziano da Fome Zero: A experiência brasileira/ José Graziano da Silva; Mauro Eduardo Del Grossi; Caio Galvão de França (orgs.); - Brasília: MDA, 2010. Série NEAD Especial 12 (362 pág).

TELLES, L. Desvelando a economia invisível das agricultoras agroecológicas: a experiência das mulheres de Barra do Turvo, SP. Dissertação (Mestrado Programa de Pós-Graduação em Extensão Rural). Viçosa: UFV, 2018 


\section{OREVER}

TRICHES, R., M.; SILVESTRI, F. Adequação das Chamadas Públicas para Aquisição de Produtos da Agricultura Familiar para a Alimentação Escolar. Desenvolvimento em Questão - Editora Unijuí - ano 16; n. 44; jul./set. p. 233 - 259. 2018.

YIN, R. Estudo de casos: planejamento e métodos. Porto Alegre: Bookman, 2010. 